\title{
3 Research Square \\ Gene Regulation Network and prognosis analyses of PCK1 in Hepatocellular Carcinoma
}

\section{Hongbin Ma}

Eastern Hepatobiliary Surgery Hospital

\section{Yong Li}

Eastern Hepatobiliary Surgery Hospital

\section{Xiaomei Gong}

Tongji University Affiliated Shanghai Pulmonary Hospital

Liang Yang ( $\nabla$ yl2002_yang@sina.com )

Shanghai First Maternity and Infant Hospital

\section{Feiling Feng ( $\square$ ffeiling@163.com )}

Eastern Hepatobiliary Surgery Hospital

\section{Research}

Keywords: PCK1, Hepatocellular Carcinoma, mRNA expression, prognosis, Xenograft tumor, Gene networks

Posted Date: July 28th, 2020

DOl: https://doi.org/10.21203/rs.3.rs-44984/v1

License: (c) (i) This work is licensed under a Creative Commons Attribution 4.0 International License. Read Full License 


\section{Abstract}

Background: The cytoplasmic isoform of phosphoenolpyruvate carboxykinase (PCK1) is a rate-limiting enzyme in gluconeogenesis. Mounting studies have shown that PCK1 plays a key role in human cancers including hepatocellular carcinoma (HCC). In this study, the mRNA expression, the prognostic value and the gene networks of PCK1 in HCC were investigated.

Methods: Expression analysis of PCK1 in HCC was obtained from Oncomine, UALCAN, Human Protein Atlas (HPA) and HCC samples. Prognostic value related to PCK1 expression in HCC patients were evaluated by Kaplan-Meier Plotter. The function effects were analyzed by constructing xenograft tumor mice. Gene functional enrichment was performed via LinkedOmics and GeneMANIA.

Results: PCK1 expression at mRNA level and protein level was both downregulated in liver cancer tissues compared with normal liver tissues. The decreased expression of PCK1 at protein level was also validated in collected HCC samples. What's more, PCK1 expression was negatively associated with cancer stages, tumor grades and metastasis nodal of HCC. Meanwhile, decreased mRNA expression of PCK1 was associated with poor overall survival of HCC patients. Furthermore, PCK1 overexpression in xenograft tumor of nude mice repressed hepatoma tumor growth and made hepatoma mice survive longer. Next, enrichment and functional interaction analysis of PCK1 in HCC by using LinkedOmics and GeneMANIA suggested that PCK1 and neighbor genes were involved in the spliceosome, cell cycle, DNA replication pathways.

Conclusions: In sum, our results reveal the PCK1 expression patterns, the potential prognosis value and predicted functional network in HCC, which illuminates the key role of PCK1 in HCC development.

\section{Background}

Hepatocellular carcinoma (HCC), the most common primary malignancy of the liver, is the fifth leading cancer that ranked second mortality rate in the world [1,2]. Nowadays, the prognosis and recurrence of HCC patients have been significantly improved for the common treatment including surgical resection, radiotherapy, chemotherapy, targeted therapy and so on $[3,4]$. Nevertheless, it is not optimistic about the 5 -year survival rate of HCC. Therefore, it is urgently needed to further investigate the underlying pathogenesis and etiology of HCC, which will contribute to the discovery of the advanced treatment and diagnostic markers.

Metabolic disorders contributes to tumorigenesis $[5,6]$. It is the major way to obtain energy in normal cells by mitochondrial oxidative phosphorylation. However, cancer cells rewire specific metabolic patterns such as aerobic glycolysis, which is also known as the "Warburg effect" [7]. Phosphoenolpyruvate carboxykinase (PCK) acts as the first rate-limiting enzyme of gluconeogenesis, which catalyzes the conversion of oxaloacetate (OAA) to phosphoenolpyruvate (PEP). It has been reported that the dysfunction of PCK is related to a series of metabolic diseases such as diabetes, fatty liver, obesity and so on. PCK1 [8]. There are two isoforms of PCK: a cytoplasmic isoform (PCK1) and a mitochondrial 
isoform (PCK2) $[9,10]$. Studies have shown that PCK was involved in tumorigenesis in certain cancers. PCK2 was found upregulated in human colon cancers and might be a useful predictor of a response to chemoradiotherapy in patients with rectal cancer [11]. In melanoma cells, upregulation of PCK1 promoted melanoma cells tumor growth in vitro and in vivo [12]. The expression level of PCK1 was negatively correlated with tumor progression in clear cell renal cell carcinoma (cCRCC), of which PCK1 suppressed cCRCC cell growth and metastasis in vitro and inhibited tumorigenesis in nude mice by blocking the aerobic glycolysis pathway [13]. However, studies showed that PCK1 was downregulated in HCC. Up to now, little is known about the expression pattern, functional role, and prognostic role of PCK1 in HCC.

As far as we know, the bioinformatics analysis has yet been applied to explore the role of the PCK1 in HCC. Based on the analyses of PCK1 gene expression patterns with pathological characteristics in HCC from online database, we demonstrated the expression patterns with clinicopathological features, prognosis, potential pathways and functions of PCK1 in HCC.

\section{Materials And Methods}

\section{Ethics statement}

This study was approved by the Academic Committee of Tongji University. All of the datasets were retrieved from the online databases and published literature, so it was confirmed that all written informed consent had been obtained.

\section{ONCOMINE database}

The mRNA expression of PCK1 in HCC was analyzed within the Oncomine database (www.oncomine.org), an integrated online cancer microarray database [22-24]. This analysis included these studies of Chen Liver [14], Roessler Liver 2, Roessler Liver [15] and Wurmbach Liver [16]using a Student's $t$ test. The cutoff of $p$ value and fold change were defined as 0.05 and 2 , respectively.

\section{UALCAN}

The relative expression of PCK1 between HCC tumors and normal liver tissues, with individual cancer stages, tumor grade or other clinicopathological features was analyzed by UALCAN [25] (http://ualcan.path.uab.edu), which was an interactive web-portal covering level 3 RNA-seq and clinical data from 31 cancer types via TCGA.

\section{Human Protein Atlas}

The expression of PCK1 at protein level between human HCC tumors and normal tissues was shown as immunohistochemistry image, which derived from the Human Protein Atlas (https://www.proteinatlas.org). The Human Protein Atlas was a website focusing on a particular aspect of the genome-wide analysis of the human proteins covering common kinds of cancers and normal tissues [26]. 


\section{Western blot}

Tissues were lysed with lysis buffer and harvested. The loading samples were quantified with BCA protein quantification kit (Yeasen). The equal tissue lysates were prepared for sodiumdodecyl sulfatepolyacrylamide gel (SDS-PAGE) electrophoresis and then transferred to nitrocellulose (NC) membranes (Millipore, Billerica, MA, USA). The NC membranes were blocked with $5 \%$ non-fat milk then incubated with the primary antibodies at $4^{\circ} \mathrm{C}$ overnight. Next, the membranes incubated with horseradish peroxidaselabelled secondary antibody (Abcam). The protein bands were detected with the enhanced chemiluminescence kit (Beyotime).

\section{Kaplan-Meier Plotter}

The prognostic value of PCK1 expression at mRNA level in HCC was analyzed by using Kaplan Meier plotter (http://kmplot.com/analysis/), which is capable to assess the effects of 54k genes on survival in 21 cancer types [27-30]. The largest datasets include breast cancer, ovarian cancer, lung cancer, and gastric cancer. The Information including the number-at-risk cases, median values of mRNA expression levels, HRs, $95 \%$ Cls and p-values was shown on the K-M plotter chart. Statically significant difference was considered when a $p$ value $<0.05$.

\section{Xenograft tumor mice}

The male nude mice (5 6 weeks old) were used for the subcutaneous xenograft model. Hepatoma cells were injected subcutaneously into the flanks of nude mice $\left(1 \times 10^{5} \mathrm{cell} /\right.$ /inoculation). For tumor weight analysis, mice were sacrificed and tumors tissues were obtained for assessment. Tumor volumes were measured every seven days after inoculation. All animal experimental procedures were approved by the Institutional Animal Care and Use Committee of Tongji University School of Medicine.

\section{cBioPortal}

The cBio Cancer Genomics Portal (http://cbioportal.org) is an open-access website including data sets of multidimensional cancer genomics [31]. We used c-BioPortal to analyze PCK1 alterations in the TCGA liver hepatocellular carcinoma (LIHC) samples.

\section{LinkedOmics}

LinkedOmics ((http://www.linkedomics.orglogin.php) is publicly available portal that includes multiomics data from all 32 TCGA Cancer types [32]. Our study used the LinkInterpreter module to perform enrichment analysis based on Gene Ontology, biological pathways, network modules, among other functional categories.

\section{GeneMANIA}


GeneMANIA is a website for constructing protein protein interaction (PPI) network by using a large amount of functional association data [33]. These association data include protein and genetic interactions, pathways, co-expression, co-localization and protein domain similarity. In our study we analyzed PCK1 associated genes networks and the predicted potential functions by using GeneMANIA.

\section{CCLE}

CCLE ( https://www.broadinstitute.org/ccle) is a website providing public access to genomic data, analysis, and visualization for about 1,457 cell lines, which was founded by the Broad Institute and the Novartis Institutes for Biomedical Research and its Genomics Institute of the Novartis Research [34]. PCK1 expression at mRNA level in cancer cell lines was investigated by the CCLE dataset.

\section{EMBL-EBI}

EMBL-EBI (https://www.ebi.ac.uk) is an open science resource providing information about gene and protein expressions across species and biological conditions such as different tissues, cell types, developmental stages and diseases [35]. PCK1 expression at mRNA level in cancer cell lines was investigated by the EMBL-EBI dataset.

\section{Results}

\section{PCK1 expression in HCC}

It has been reported that PCK1 functions as an oncogenic gene during certain tumors development [10, 13]. To evaluate the prognostic and potential clinical value of PCK1 in liver cancer, we analyzed PCK1 expression at mRNA and protein levels using ONCOMINE database (www.oncomine. org) and Human Protein Atlas (https://www.proteinatlas.org). As shown in Figure 1, PCK1 was mostly downregulated at mRNA level among 20 types of cancers including the liver cancer compared to normal tissues by using ONCOMINE database. PCK1 expression was significantly decreased in HCC tissues in four datasets (Figure 2 and Table 1). In Chen Liver dataset, PCK1 down-regulation was found in HCC tissues compared with normal tissues with a fold change of $5.155(p=1.15 E-17)$ (Figure 2A) [14]. The result from Roessler Liver 2 dataset showed that there was 7.603-fold ( $p=7.05 \mathrm{E}-48)$ decrease in PCK1 mRNA expression in HCC tissues (Figure 2B) [15]. Roessler found 10.352-fold decrease in PCK1 mRNA expression in HCC samples $(p=6.58 E-6)$ and Roessler observed 4.351 -fold decrease in PCK1 mRNA expression in HCC tissues ( $p=3.24 E-6)$ (Figure 2C and 2D) [16]. Next, we analyzed the protein expression pattern of PCK1 in HCC using the Human Protein Atlas. We observed that PCK1 was not detected in HCC tissues while low expressed in normal liver tissues (Figure 3A). Moreover, we detected PCK1 expression in 6 pairs of HCC tissue samples. PCK1 expression was also downregulated in HCC tissues compared to adjacent normal liver tissues (Figure 3B). Taken together, our results showed that PCK1 was downregulated in HCC at transcription and protein levels. 
Furthermore, we assessed the clinical pathological relevance of PCK1 expression, TCGA data of 371 hepatocellular carcinoma (HCC) patients and 50 controls were downloaded from UALCAN (http://ualcan.path.uab.edu/analysis.html). Consistently, PCK1 was also remarkably decreased in primary HCC tissues compared to normal samples (Figure 4A, $p<0.001$ ). What's more, PCK1 was expressed at mRNA level less and less with more advanced individual cancer stages and tumor grades (Figure 4B and 4C). The lowest expression of PCK1 was found in stage 3 but not stage 4 perhaps for the reason that there were only 6 samples in HCC patients at stage 4. Similarly, the expression of PCK1 at mRNA level was significantly decreased associated with tumor grades. The expression of PCK1 tended to be lower as the tumor grade increased (Figure 4C). In addition, it seemed that PCK1 was also related to the nodal metastasis status of HCC patients, lower expression of PCK1 associated with increased nodal metastasis except for N1 (The sample size was too small only including 4 samples shown in Figure 4D). Above all, the results suggested that PCK1 expression was closely related to the clinicopathological characteristics in HCC patients.

We also detected PCK1 expression in HCC cell lines by using the Cancer Cell Line Encyclopedia (CCLE) (https://www.broadinstitute.org/ccle) and the European Bioinformatics Institute (EMBL-EBI) (https://www.ebi.ac.uk/gxa/home) as shown in Supplementary Figure 1. We discovered that PCK1 expression was almost decreased in cell lines of liver (Supplementary Figure $1 \mathrm{~A}$ ) via CCLE and the EMBLEBI result showed that PCK1 was downregulated in most cell lines of liver (Supplementary Figure 1B).

\section{The Prognostic Value of PCK1 in HCC patients}

Moreover, we investigated the prognostic values of PCK1 in HCC patients via the Kaplan-Meier plotter (http://kmplot.com/analysis/). Results showed that the low expression of PCK1 at mRNA level was associated with better overall survival (OS) (HR=0.61 (0.42-0.86), $p=0.005$, Figure 5). The analysis suggested that the transcription expression of PCK1 might be considered as an independent prognostic factor for OS of HCC patients.

\section{Antitumor effects of PCK1 in vivo}

Next, we investigated the in vivo effects of PCK1 on hepatoma tumorigenesis, PCK1 overexpressing cells and control cells were subcutaneously inoculated into nude mice. We observed that the mean tumor volume of PCK1-overexpressing group was significantly smaller than the control group as shown in Figure 2E. The mice were sacrificed and the tumors were weighted after 28-day inoculation. The mean tumor weight of PCK1-overexpressing group was lower than the control group (Figure 6B). Consistently, the mean tumor volumn of PCK1-overexpressing group was also smaller than the control group (Figure 6C). As above analyzed, high expression of PCK1 was associated with poor overall survival of HCC patients, we wondered the overall survival of PCK1-overexpressing of hepatoma mice. We observed that the hepatoma mice with high expression of PCK1 survived longer than the control group (Figure 6D). The in vivo results confirmed that high PCK1 expression of HCC patients tend to be a better prognosis.

\section{Predicted functions and pathways of PCK1 in HCC}


In order to further explore the functional network of PCK1 on HCC development, we performed the enrichment and functional interaction analysis of PCK1 in HCC by using LinkedOmics. The result of the volcano plot showed that there were 2987 genes (dark dots by the red line) positively correlated with PCK1 while 6599 genes (dark dots by the green line) negatively correlated with PCK1 in statistical significance (false discovery rate $(F D R)<0.01$, Figure $7 A$ ). The 50 representative genes sets significantly negative and positive related with PCK1 were presented as the heat maps (Figure 7B and 7C). These results revealed the co-expression genes associated with PCK1 in HCC at transcription level. Functions of PCK1 were analyzed by gene set enrichment analysis (GSEA). Results showed that genes differentially expressed in correlation with PCK1 participated in the main biological processes such as biological regulation, metabolic process, response to stimulus and multicellular organismal process, which were mainly distributed on the membrane and nucleus. Moreover, the molecular functions such as protein binding and ion binding were predominantly affected by PCK1 and its neighboring genes (Figure 8A-8C). KEGG pathway analysis showed enrichment in the spliceosome, cell cycle, DNA replication pathways (Figure 8D).

Moreover, the protein-protein interaction network analyzed by GeneMANIA revealed that the correlated genes with PCK1 was responsible mainly for cellular response to xenobiotic stimulus, xenobiotic metabolic process, drug metabolic process and uronic acid metabolic process (Figure 9).

\section{Discussions}

Previous studies have showed that abnormal expressions and dysfunctions of PCK1 advance certain cancers [10-13]. Lin et.al found that downregulation of PCK1 promoted TXNRD1 expression and hepatoma cell growth via the Nrf2/Keap1 pathway [17]. To further investigate the detailed potential functional and regulatory networks of PCK1 in HCC, we conducted comprehensive bioinformatics analysis of PCK1 in HCC based on the public literature and online databases. Herein, the expression, the prognostic value, the enrichment of functional networks and the mutation of PCK1 in HCC were analyzed and summarized. we hope our findings could contribute to the treatment and prognosis for patients with HCC.

Our study from a variety of perspectives demonstrated the importance of PCK1 in HCC development. Our results revealed that expressions of mRNA and protein of PCK1 was downregulated in HCC samples. Besides, PCK1 expression was also downregulated in liver cancer cell lines. Next, PCK1 mRNA level was negatively associated with HCC patients' cancer stages, tumor grades and nodal metastasis. What's more, decreased mRNA expression of PCK1 was closely related to poor overall survival of liver cancer patients. Finally, enrichment and functional interactive analysis showed that PCK1 and neighboring genes were mainly involved in the biological processes such as biological regulation, metabolic process, response to stimulus and multicellular organismal process, which were mainly distributed on the membrane and nucleus. Moreover, the molecular functions such as protein binding and ion binding were predominantly affected by PCK1 and its neighboring genes. PCK1 and neighboring genes were responsible for the regulation of spliceosome, cell cycle, DNA replication pathways. 
Downregulation of PCK1 was found in HCC tissues and was associated with poor prognosis of HCC patients [18]. Functional study revealed that forced expression of PCK1 promoted liver cancer cells apoptosis and suppressed liver tumorigenesis in mice. Similarly, in our study, PCK1 expression at mRNA and protein levels were also found in HCC tissues, mRNA expression of PCK1 was significantly associated with HCC patients' individual cancer stages, tumor grades and nodal metastasis. And that, decreased mRNA expression of PCK1 was also significantly associated with poor survival of HCC patients. Taken together, our findings discussed above indicated that PCK1 acted as a tumor suppressor role in HCC.

Studies have shown that mutagenesis could aggravate human cancers [19-21]. We wondered whether PCK1 gene alterations had effects on HCC tumorigenesis. The data of the types and frequency of PCK1 alterations in HCC patients were obtained from cBioPortal (www.cBioPortal.org) (Supplementary Figure 2). PCK1 was altered in 40 of $363(11 \%)$ HCC cases (Supplementary Figure 2). These alterations were mRNA upregulation in 25 cases (6.89\%), mutation in 7 cases $(1.93 \%)$, amplification in 4 cases $(1.1 \%)$, and multiple alterations in 2 cases $(0.55 \%)$ (Table 2$)$. On the whole, amplification is the most common type of PCK1 in HCC. These results suggested that mutagenesis of PCK1 might not occurred frequently in HCC.

However, there are some limitations in our research. Firstly, we did not explore the detailed molecular mechanism of PCK1 in HCC tumorigenesis, which could be included in the follow-up plan. Secondly, we did not make any analysis of the diagnostic role of PCK1 in HCC.it is worth to be investigated in the future research.

To sum up, we comprehensively study the expression and prognostic value of PCK1 in HCC and have important implications for the potential molecular mechanisms of PCK1-involved HCC tumor growth and development. Our results indicated that PCK1 was down-regulated in HCC and was closely related to the clinicopathological features such as the tumor stage, the tumor grade and the nodal metastasis status of HCC patients, suggesting that PCK1 played an important role in HCC development. Moreover, low PCK1 expression was associated with poor survival which could be considered as an independent prognostic factor for high risk HCC patient. Our study indicated that PCK1 might be a potential prognostic markers in HCC patients.

\section{Conclusions}

In summary, we comprehensively study the expression and prognostic value of PCK1 in HCC and have important implications for the potential molecular mechanisms of PCK1-involved HCC tumor growth and development.

\section{Declarations}

\section{Ethics approval and consent to participate}


The research was approved by the Academic Committee of Tongji University. All written informed consent had been obtained.

\section{Consent for publication}

All presentations have consent for publication.

\section{Availability of data and material}

All data generated or analysed during this study are included in this published article [and its supplementary information files].

\section{Competing interests}

All authors declared no conflicts of interests with this paper.

\section{Funding}

None

\section{Authors' contributions}

Data curation, Yong Li and Xiaomei Gong; Formal analysis, Yong Li and Xiaomei Gong; Supervision, Liang Yang; Writing - original draft, Hongbin Ma; Writing - review \& editing, Liang Yang and Feiling Feng.

\section{Acknowledgements}

We thank for Genex Health Co., Ltd (Beijing, China) technical guidance during the preparation of this paper.

\section{Abbreviations}

PCK1: phosphoenolpyruvate carboxykinase

HCC: hepatocellular carcinoma

\section{References}

1. Ghouri YA, Mian I, Rowe JH. Review of hepatocellular carcinoma: Epidemiology, etiology, and carcinogenesis. J Carcinog. 2017;16:1.

2. Torre LA, Bray F, Siegel RL, Ferlay J, Lortet-Tieulent J, Jemal A. Global cancer statistics, 2012. CA Cancer J Clin. 2015;65:87-108.

3. Zhang X, Bai Y, Xu L, Zhang B, Feng S, Xu L, Zhang H, Xu L, Yang P, Niu T, et al. Clinical and morphomolecular classifiers for prediction of hepatocellular carcinoma prognosis and recurrence after 
surgical resection. Hepatol Int. 2019;13:715-25.

4. Tabrizian P, Jibara G, Shrager B, Schwartz M, Roayaie S. Recurrence of hepatocellular cancer after resection: patterns, treatments, and prognosis. Ann Surg. 2015;261:947-55.

5. Hsu PP, Sabatini DM. Cancer cell metabolism: Warburg and beyond. Cell. 2008;134:703-7.

6. Hanahan D, Weinberg RA. Hallmarks of cancer: the next generation. Cell. 2011;144:646-74.

7. Vander HMG, Cantley LC, Thompson CB. Understanding the Warburg effect: the metabolic requirements of cell proliferation. Science. 2009;324:1029-33.

8. Beale EG, Harvey BJ, Forest C. PCK1 and PCK2 as candidate diabetes and obesity genes. Cell Biochem Biophys. 2007:48:89-95.

9. Méndez-Lucas A, Duarte JA, Sunny NE, Satapati S, He T, Fu X, Bermúdez J, Burgess SC, Perales JC. PEPCK-M expression in mouse liver potentiates, not replaces, PEPCK-C mediated gluconeogenesis. $J$ Hepatol. 2013;59:105-13.

10. Montal ED, Dewi R, Bhalla K, Ou L, Hwang BJ, Ropell AE, Gordon C, Liu WJ, DeBerardinis RJ, Sudderth $J$, et al. PEPCK Coordinates the Regulation of Central Carbon Metabolism to Promote Cancer Cell Growth. Mol Cell. 2015;60:571-83.

11. Park JW, Kim SC, Kim WK, Hong JP, Kim KH, Yeo HY, Lee JY, Kim MS, Kim JH, Yang SY, et al. Expression of phosphoenolpyruvate carboxykinase linked to chemoradiation susceptibility of human colon cancer cells. BMC Cancer. 2014;14:160.

12. Li Y, Luo S, Ma R, Liu J, Xu P, Zhang H, Tang K, Ma J, Zhang Y, Liang X, et al. Upregulation of cytosolic phosphoenolpyruvate carboxykinase is a critical metabolic event in melanoma cells that repopulate tumors. Cancer Res. 2015;75:1191-6.

13. Shi L, An S, Liu Y, Liu J, Wang F. PCK1 Regulates Glycolysis and Tumor Progression in Clear Cell Renal Cell Carcinoma Through LDHA. Onco Targets Ther. 2020;13:2613-27.

14. Chen X, Cheung ST, So S, Fan ST, Barry C, Higgins J, Lai KM, Ji J, Dudoit S, Ng IO, et al. Gene expression patterns in human liver cancers. Mol Biol Cell. 2002;13:1929-39.

15. Roessler S, Jia HL, Budhu A, Forgues M, Ye QH, Lee JS, Thorgeirsson SS, Sun Z, Tang ZY, Qin LX, et al. A unique metastasis gene signature enables prediction of tumor relapse in early-stage hepatocellular carcinoma patients. Cancer Res. 2010;70:10202-12.

16. Wurmbach E, Chen YB, Khitrov G, Zhang W, Roayaie S, Schwartz M, Fiel I, Thung S, Mazzaferro V, Bruix J, et al. Genome-wide molecular profiles of HCV-induced dysplasia and hepatocellular carcinoma. Hepatology. 2007;45:938-47.

17. Tuo L, Xiang J, Pan X, Gao Q, Zhang G, Yang Y, Liang L, Xia J, Wang K, Tang N. PCK1 Downregulation Promotes TXNRD1 Expression and Hepatoma Cell Growth via the Nrf2/Keap1 Pathway. Front Oncol. 2018;8:611.

18. Liu MX, Jin L, Sun SJ, Liu P, Feng X, Cheng ZL, Liu WR, Guan KL, Shi YH, Yuan HX, et al. Metabolic reprogramming by PCK1 promotes TCA cataplerosis, oxidative stress and apoptosis in liver cancer cells and suppresses hepatocellular carcinoma. Oncogene. 2018;37:1637-53. 
19. Basu AK. DNA Damage, Mutagenesis and Cancer. Int J Mol Sci. 2018;19.

20. Alexandrov LB, Nik-Zainal S, Wedge DC, Aparicio SA, Behjati S, Biankin AV, Bignell GR, Bolli N, Borg A, Børresen-Dale AL, et al. Signatures of mutational processes in human cancer. Nature. 2013;500:41521.

21. El-Kenawi A, Ruffell B. Inflammation, ROS, and Mutagenesis. Cancer Cell. 2017;32:727-9.

22. Williams HL, Walsh K, Diamond A, Oniscu A, Deans ZC. Validation of the Oncomine ${ }^{\text {TM }}$ focus panel for next-generation sequencing of clinical tumour samples. Virchows Arch. 2018;473:489-503.

23. Rhodes DR, Yu J, Shanker K, Deshpande N, Varambally R, Ghosh D, Barrette T, Pandey A, Chinnaiyan AM. ONCOMINE: a cancer microarray database and integrated data-mining platform. Neoplasia. 2004;6:1-6.

24. Rhodes DR, Kalyana-Sundaram S, Mahavisno V, Varambally R, Yu J, Briggs BB, Barrette TR, Anstet MJ, Kincead-Beal C, Kulkarni P, et al. Oncomine 3.0: genes, pathways, and networks in a collection of 18,000 cancer gene expression profiles. Neoplasia. 2007;9:166-80.

25. Chandrashekar DS, Bashel B, SAH B, Creighton CJ, Ponce-Rodriguez I, BVSK C, Varambally S. UALCAN: A Portal for Facilitating Tumor Subgroup Gene Expression and Survival Analyses. Neoplasia. 2017;19:649-58.

26. Asplund A, Edqvist PH, Schwenk JM, Pontén F. Antibodies for profiling the human proteome-The Human Protein Atlas as a resource for cancer research. Proteomics. 2012;12:2067-77.

27. Nagy Á, Lánczky A, Menyhárt O, Győrffy B. Validation of miRNA prognostic power in hepatocellular carcinoma using expression data of independent datasets. Sci Rep. 2018;8:9227.

28. Menyhárt O, Nagy Á, Győrffy B. Determining consistent prognostic biomarkers of overall survival and vascular invasion in hepatocellular carcinoma. R Soc Open Sci. 2018;5:181006.

29. Lánczky A, Nagy Á, Bottai G, Munkácsy G, Szabó A, Santarpia L, Győrffy B. miRpower: a web-tool to validate survival-associated miRNAs utilizing expression data from 2178 breast cancer patients. Breast Cancer Res Treat. 2016;160:439-46.

30. Szász AM, Lánczky A, Nagy Á, Förster S, Hark K, Green JE, Boussioutas A, Busuttil R, Szabó A, Győrffy B. Cross-validation of survival associated biomarkers in gastric cancer using transcriptomic data of 1,065 patients. Oncotarget. 2016;7:49322-33.

31. Gao J, Aksoy BA, Dogrusoz U, Dresdner G, Gross B, Sumer SO, Sun Y, Jacobsen A, Sinha R, Larsson E, et al. Integrative analysis of complex cancer genomics and clinical profiles using the cBioPortal. Sci Signal. 2013;6:pl1.

32. Vasaikar SV, Straub P, Wang J, Zhang B. LinkedOmics: analyzing multi-omics data within and across 32 cancer types. Nucleic Acids Res. 2018;46:D956-6D963.

33. Warde-Farley D, Donaldson SL, Comes O, Zuberi K, Badrawi R, Chao P, Franz M, Grouios C, Kazi F, Lopes CT, et al. The GeneMANIA prediction server: biological network integration for gene prioritization and predicting gene function. Nucleic Acids Res. 2010;38:W214-20. 
34. Barretina J, Caponigro G, Stransky N, Venkatesan K, Margolin AA, Kim S, Wilson CJ, Lehár J, Kryukov GV, Sonkin D, et al. The Cancer Cell Line Encyclopedia enables predictive modelling of anticancer drug sensitivity. Nature. 2012;483:603-7.

35. Li W, Cowley A, Uludag M, Gur T, McWilliam H, Squizzato S, Park YM, Buso N, Lopez R. The EMBL-EBI bioinformatics web and programmatic tools framework. Nucleic Acids Res. 2015;43:W580-4.

\section{Tables}

Table 1

\begin{tabular}{llllll}
\hline & Types of HCC VS. Liver & Fold Change & P value & T-test & Ref \\
\hline PCK1 & Hepatocellular Carcinoma & -5.155 & $1.15 \mathrm{E}-17$ & -9.667 & Chen Liver \\
& Hepatocellular Carcinoma & -7.603 & $7.05 \mathrm{E}-48$ & -18.159 & Roessler Liver 2 \\
& Hepatocellular Carcinoma & -4.351 & $3.24 \mathrm{E}-6$ & -5.154 & Wurmbach Liver \\
& Hepatocellular Carcinoma & -10.352 & $6.58 \mathrm{E}-6$ & -5.521 & Roessler Liver \\
\hline
\end{tabular}

Table 2 PCK1 Gene Alterations of Hepatocellular Carcinoma

\begin{tabular}{ccc}
\hline Types of Alteration & Cases & Frequency \\
Mutation & 7 & $1.93 \%$ \\
Amplification & 4 & $1.1 \%$ \\
mRNA High & 25 & $6.89 \%$ \\
Multiple Alterations & 2 & $0.55 \%$ \\
\hline Total & $38 / 363$ & $10.47 \%$ \\
\hline
\end{tabular}




\begin{tabular}{|c|c|c|}
\hline & \multicolumn{2}{|c|}{$\begin{array}{c}\text { PCK1 } \\
\text { Cancer } \\
\text { vs. } \\
\text { Normal }\end{array}$} \\
\hline Bladder Cancer & & 2 \\
\hline Brain and CNS Cancer & & 6 \\
\hline Breast Cancer & & 21 \\
\hline Cervical Cancer & & \\
\hline Colorectal Cancer & & 23 \\
\hline Esophageal Cancer & & 1 \\
\hline Gastric Cancer & 1 & \\
\hline Head and Neck Cancer & & 1 \\
\hline Kidney Cancer & & 6 \\
\hline Leukemia & & \\
\hline Liver Cancer & & 4 \\
\hline Lung Cancer & 1 & \\
\hline Lymphoma & & 1 \\
\hline Melanoma & & 2 \\
\hline Myeloma & & \\
\hline Other Cancer & 1 & 2 \\
\hline Ovarian Cancer & & \\
\hline Pancreatic Cancer & & 1 \\
\hline Prostate Cancer & & 1 \\
\hline Sarcoma & 1 & 10 \\
\hline Significant Unique Analyses & 4 & 80 \\
\hline Total Unique Analyses & & \\
\hline
\end{tabular}

\section{Figure 1}

Transcription levels of PCK1 in different types of cancers (Oncomine). Cut-off of $p$ value and fold change were as following: $p$ value: 0.05 , fold change: 2.0 , gene rank: $10 \%$, data type: mRNA. 
A

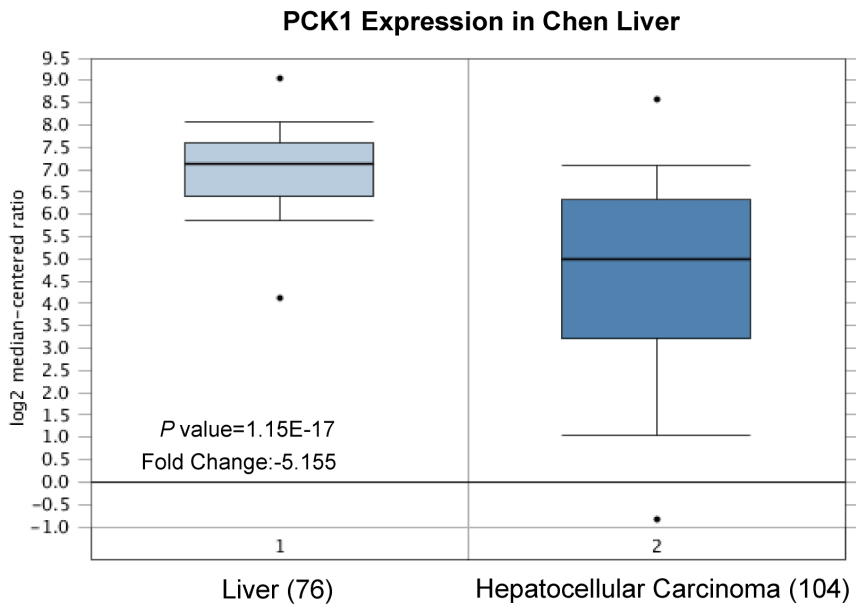

C

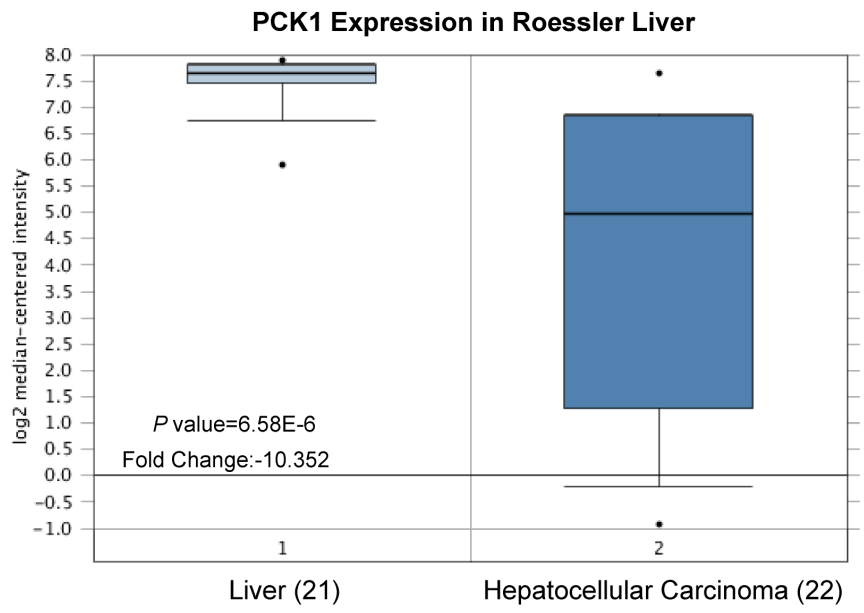

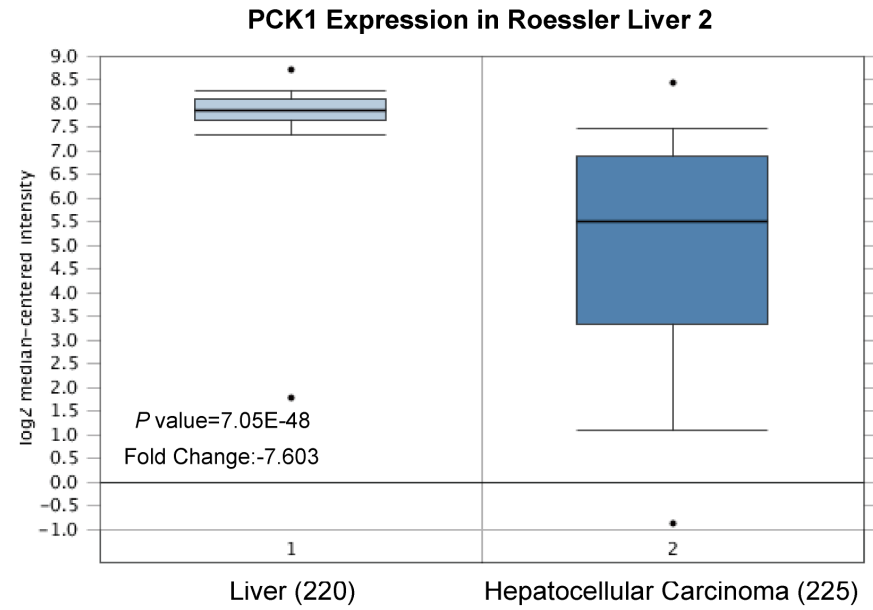

D

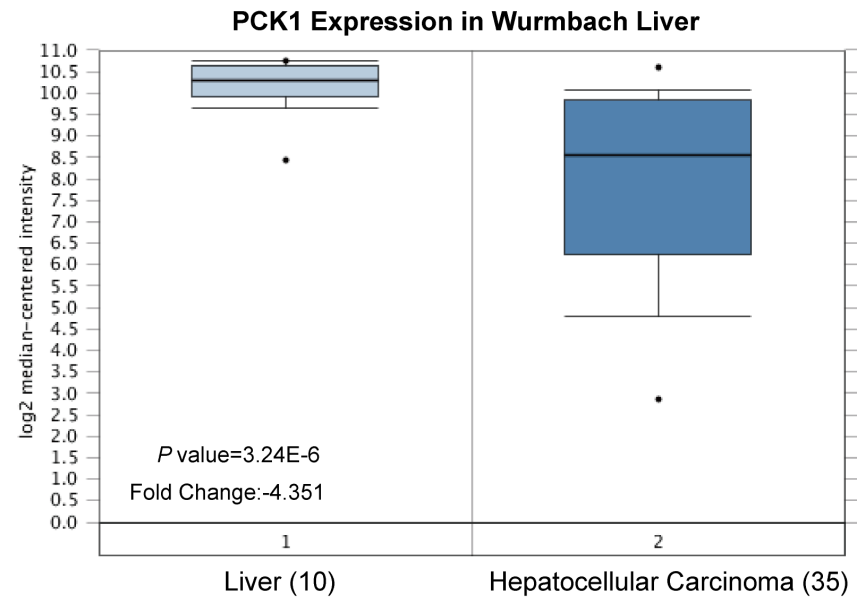

Figure 2

Transcriptional levels of PCK1 in hepatocellular carcinoma (Oncomine). PCK1 expression at mRNA level was decreased in hepatocellular carcinoma than in the normal liver tissue. Fold changes and associated $\mathrm{p}$ values were shown in the chart. (A-D) Box plots displayed PCK1 mRNA levels in Chen Liver, Roessler Liver 2, Roessler Liver and Wurmbach Liver, respectively 
A

\section{Normal}

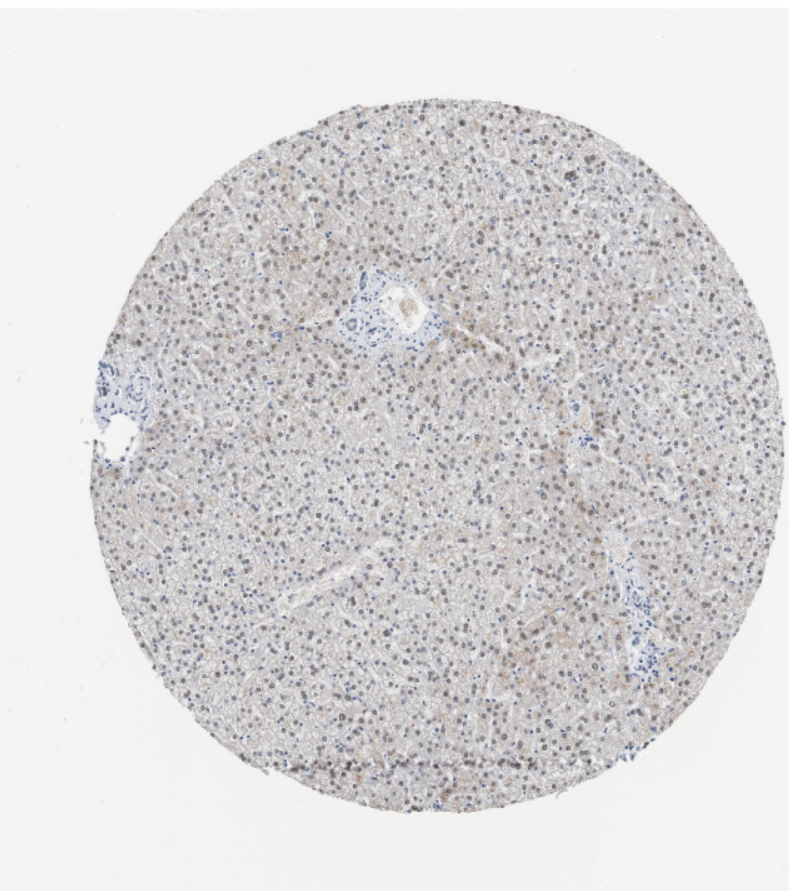

staining: Low

\section{Cancer}

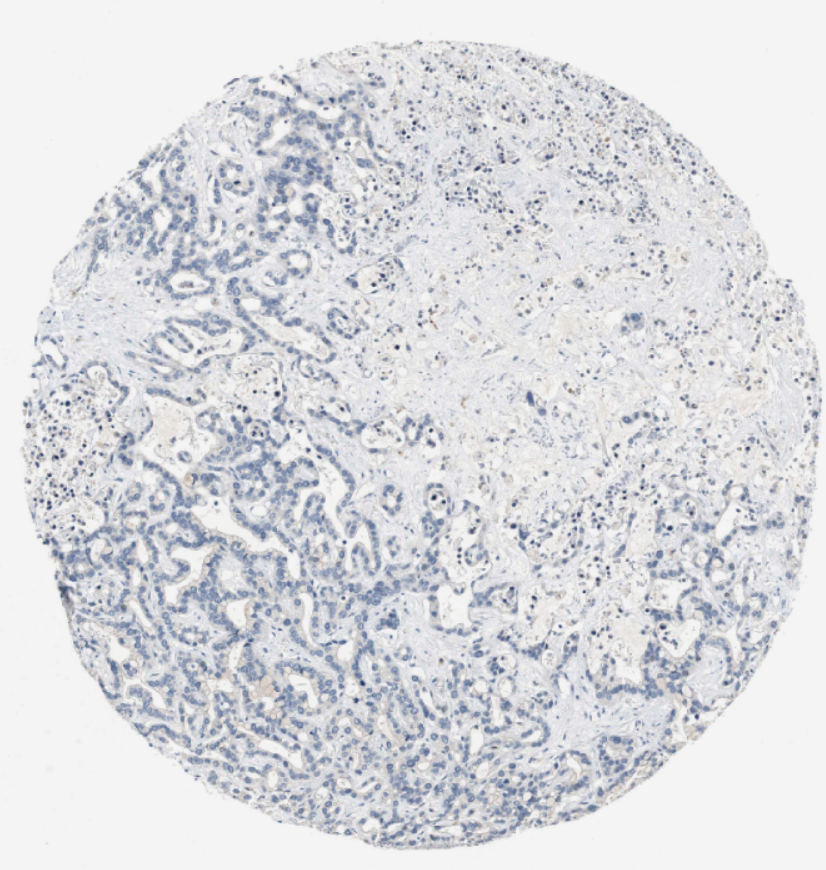

staining: Not detected

B

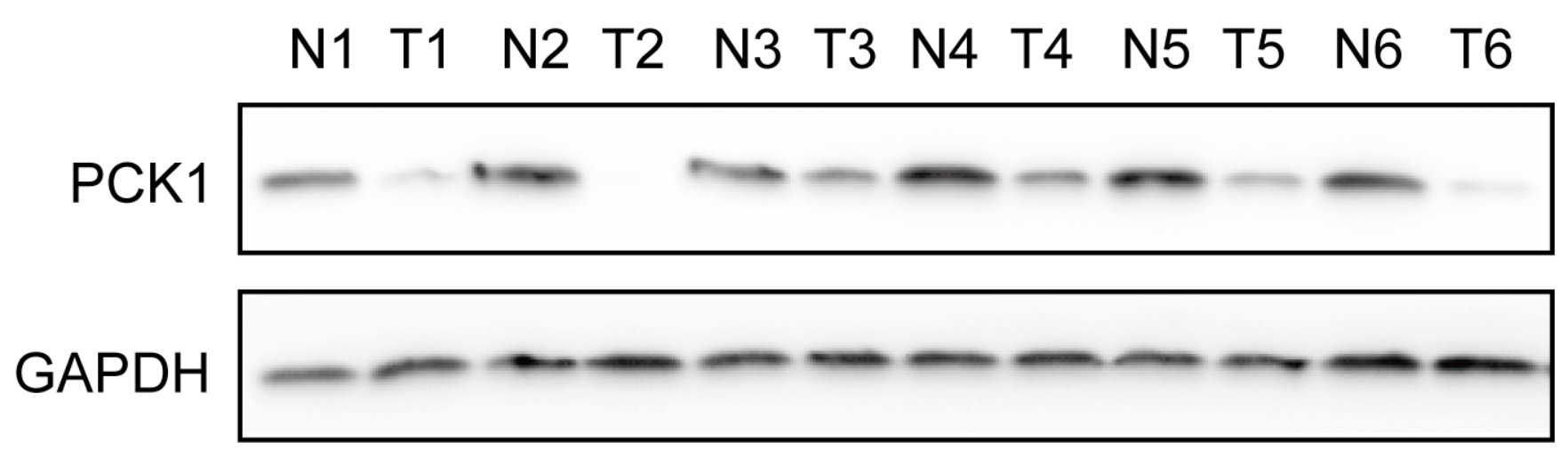

Figure 3

Protein level of PCK1 in HCC tissues and normal liver tissues. (A) PCK1 protein was not detected in HCC tissues whereas low expressed in normal liver tissues via Human Protein Atlas. (B) Western blot analysis of PCK1 in six pairs of hepatocellular carcinoma tissues samples. GAPDH was used as the loading control. 
A

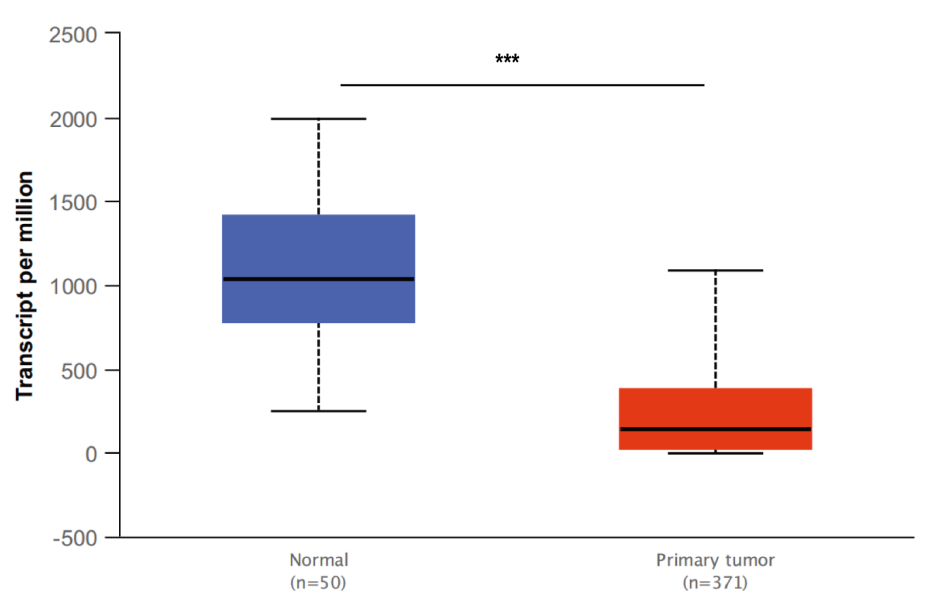

C

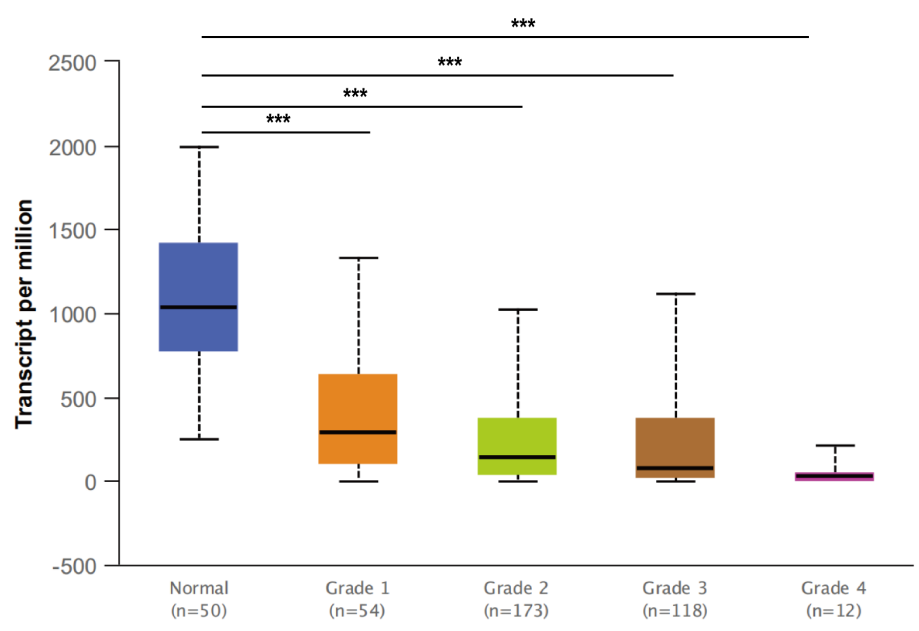

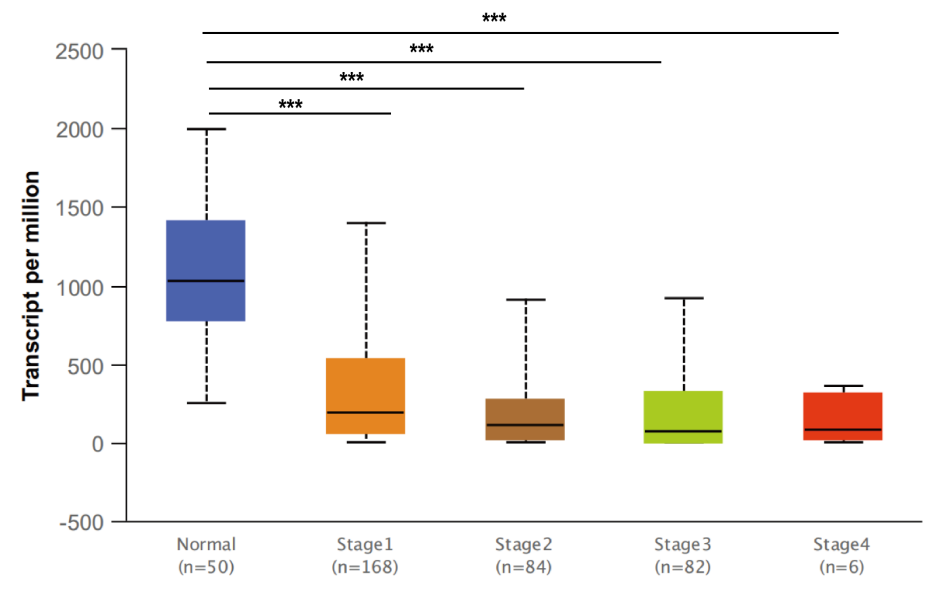

D

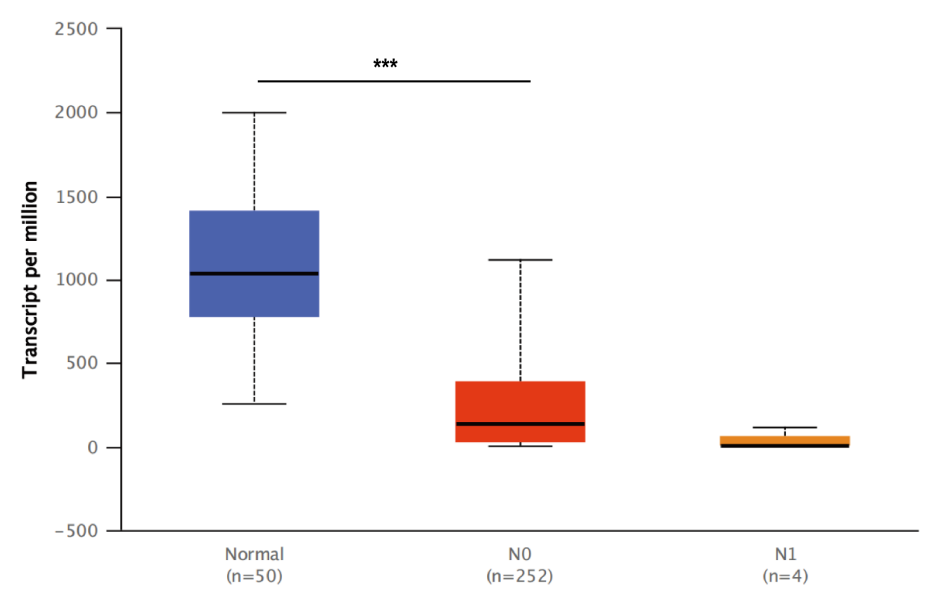

Figure 4

The mRNA expression patterns of PCK1 in HCC with clinicopathological parameters (UALCAN) (A) Relative expression of PCK1 in normal and HCC samples. (B) Relative expression of PCK1 in HCC patients at individual cancer stages. (C) Relative expression of PCK1 in HCC patients with different tumor grades. (D) Relative expression of PCK1 in HCC patients with nodal metastasis status. ${ }^{* \star *} p<0.001$ 


\section{PCK1 (5105)}

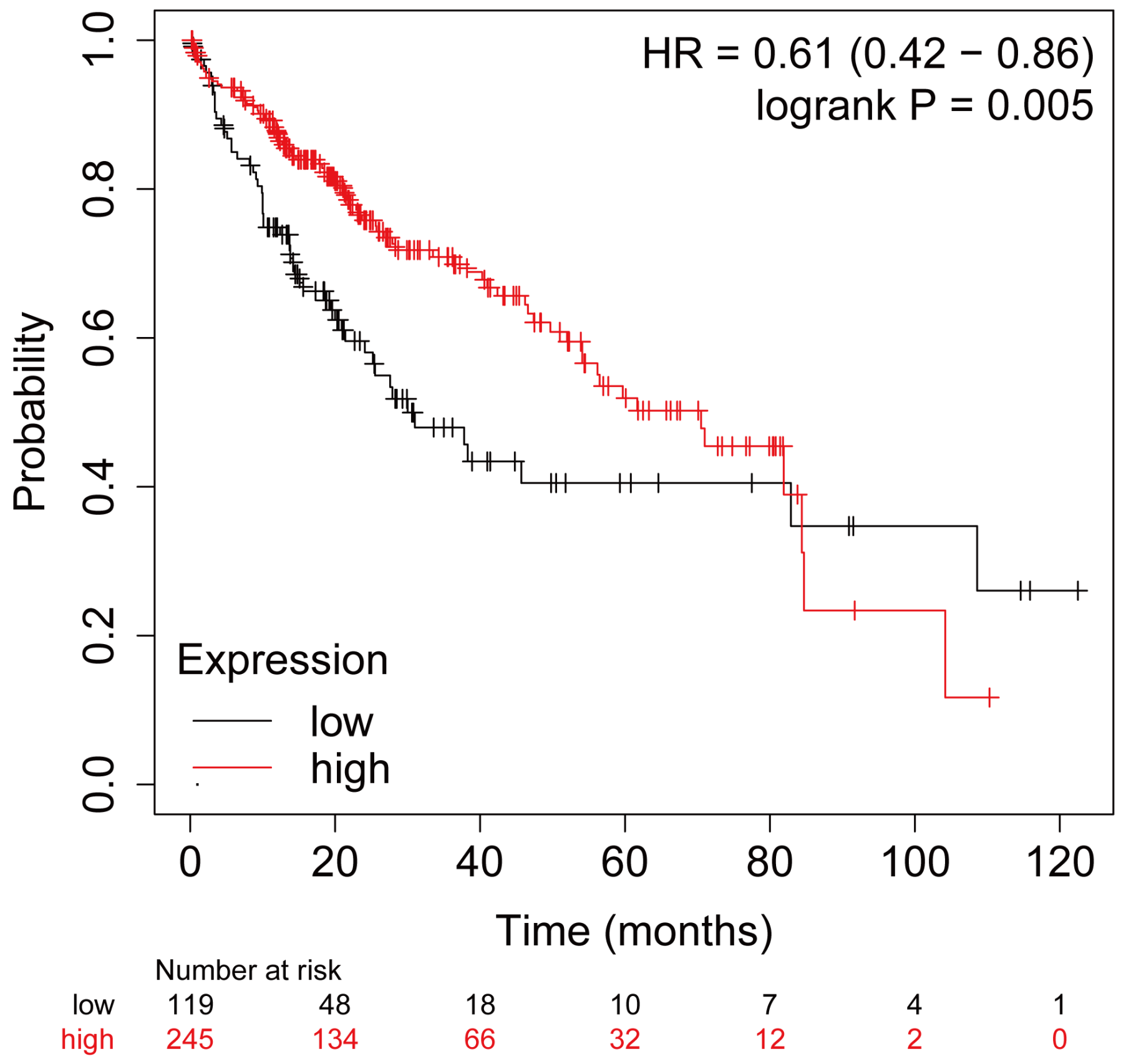

Figure 5

Prognostic value of mRNA expression of PCK1 in HCC patients analyzed (Kaplan-Meier Plotter). The prognostic value of PCK1 expression at mRNA level in HCC patients analyzed by Kaplan-Meier Plotter. 
A

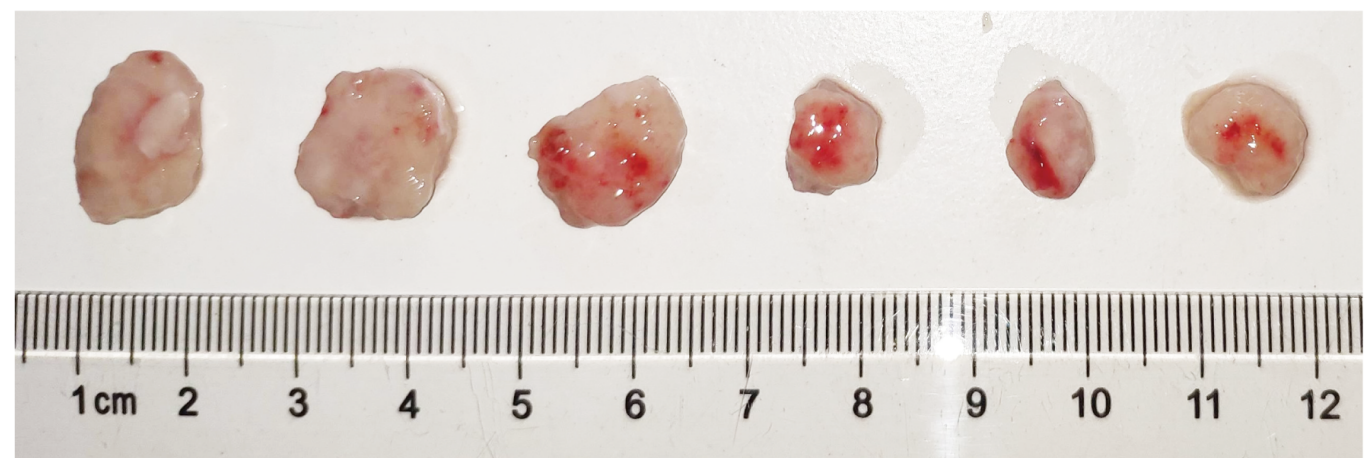

B

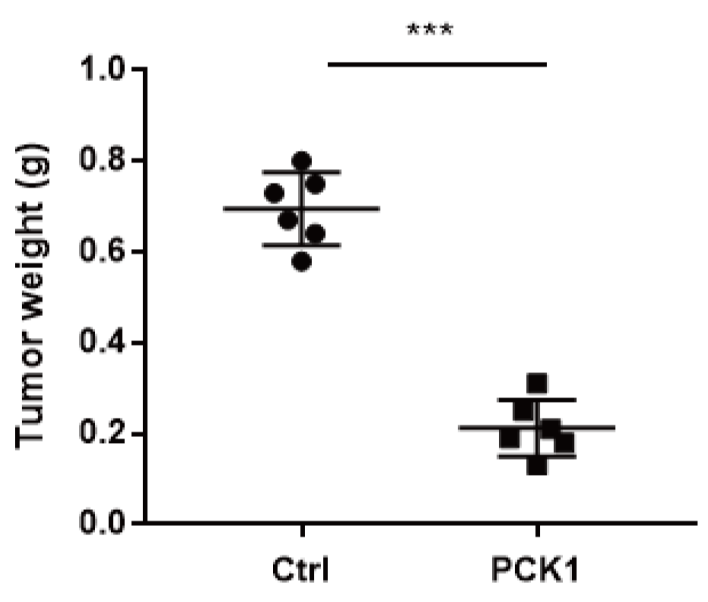

C

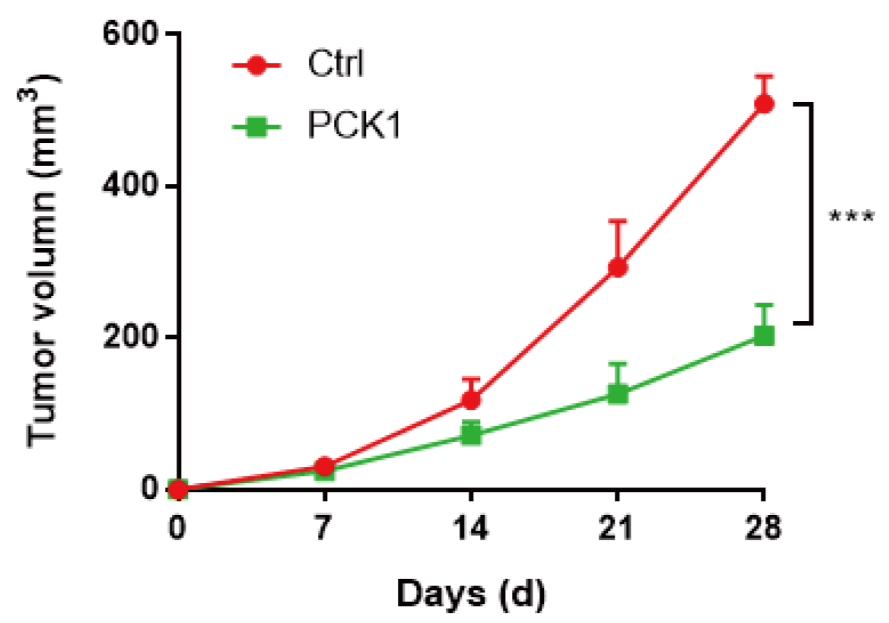

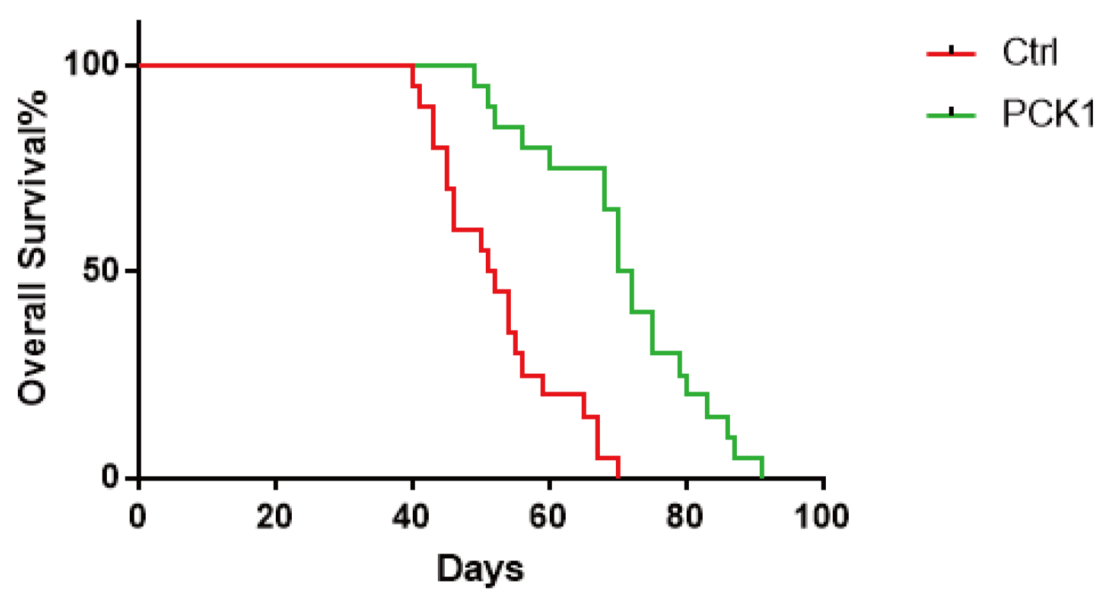

Figure 6

PCK1 overexpression suppresses tumorigenesis in vivo. (A) Representative images of tumor in all groups. PCK1 overexpression inhibited tumor growth in xenograft tumors. The overexpression of PCK1 and control MHCC97H cells were subcutaneously injected into nude mice $(n=6)$. The tumor tissues were harvested after the nude mice sacrificed 28 days following injection. (B) The tumor weight were measured on day-28 after inoculation. (C) The tumor volume was measured every week after inoculation. 
The tumor growth curve was drawn as shown. The mean tumor volume of PCK1 overexpression group was obviously decreased compared to control group. (D) The overall survival of xenograft hepatoma mice was calculated. $(n=20)$.

A

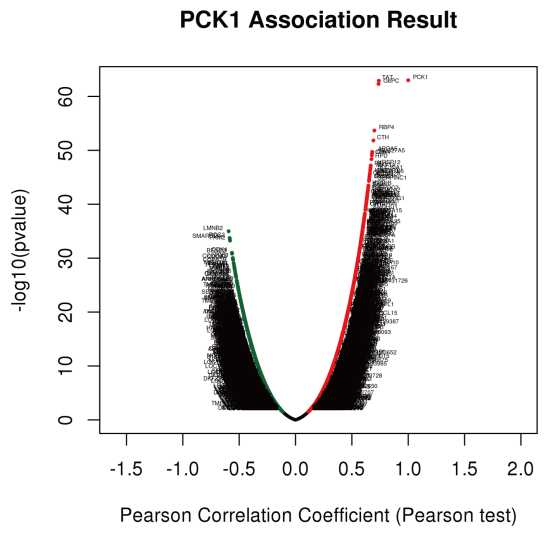

B

Negatively Correlated Significant Genes

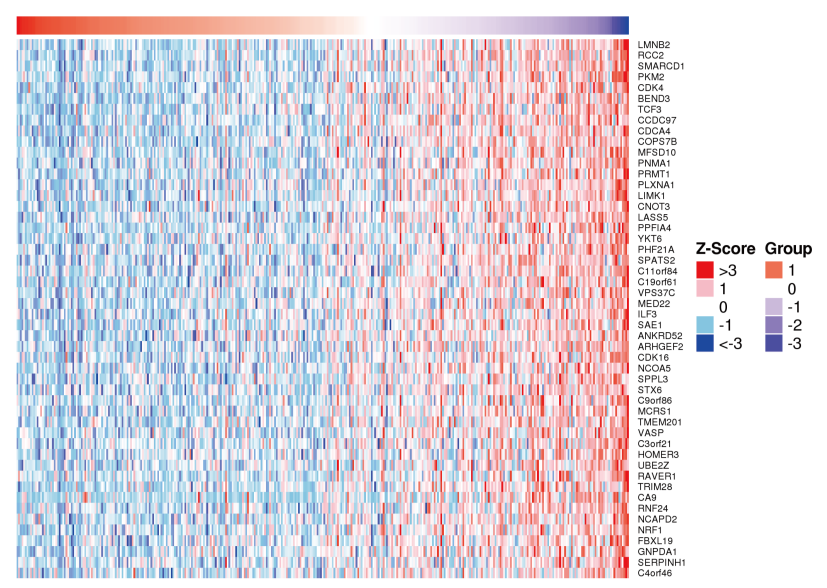

C

Positively Correlated Significant Genes

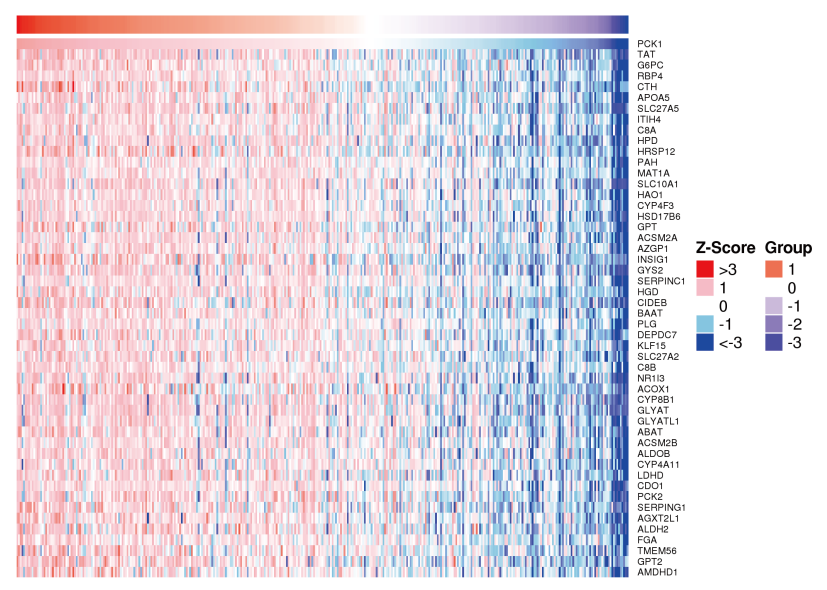

Figure 7

Correlated genes with PCK1 in HCC (LinkedOmics). (A) Pearson correlations between PCK1 and genes coexpressed in HCC. (B-C) Genes negatively and positively correlated with PCK1 (TOP 50) in HCC as shown 
in heat maps. Red indicates positively correlated genes and blue indicates negatively correlated genes.

A

GO: Biological Process

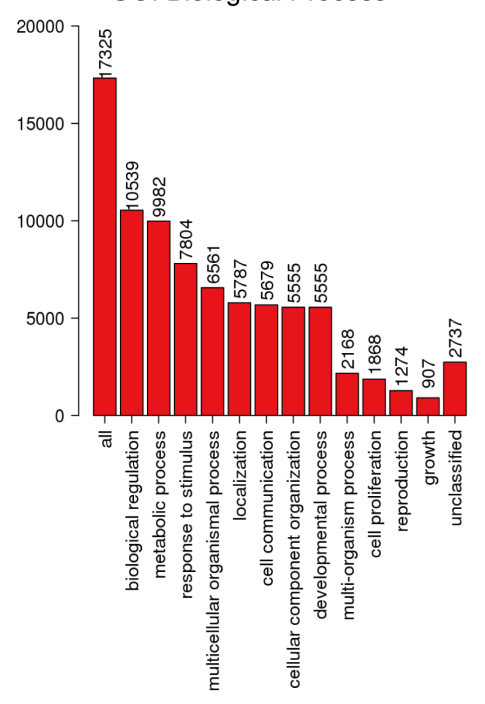

B

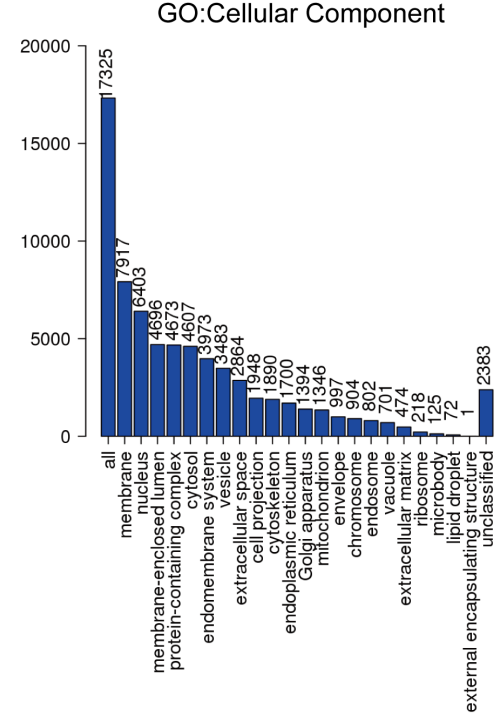

C

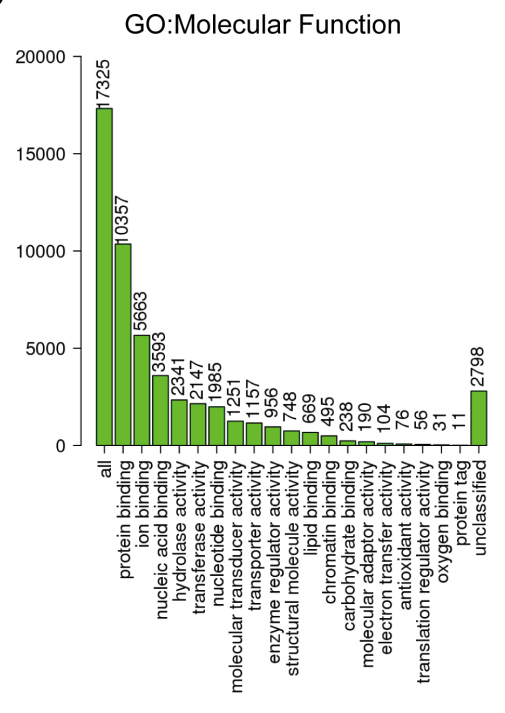

D

KEGG

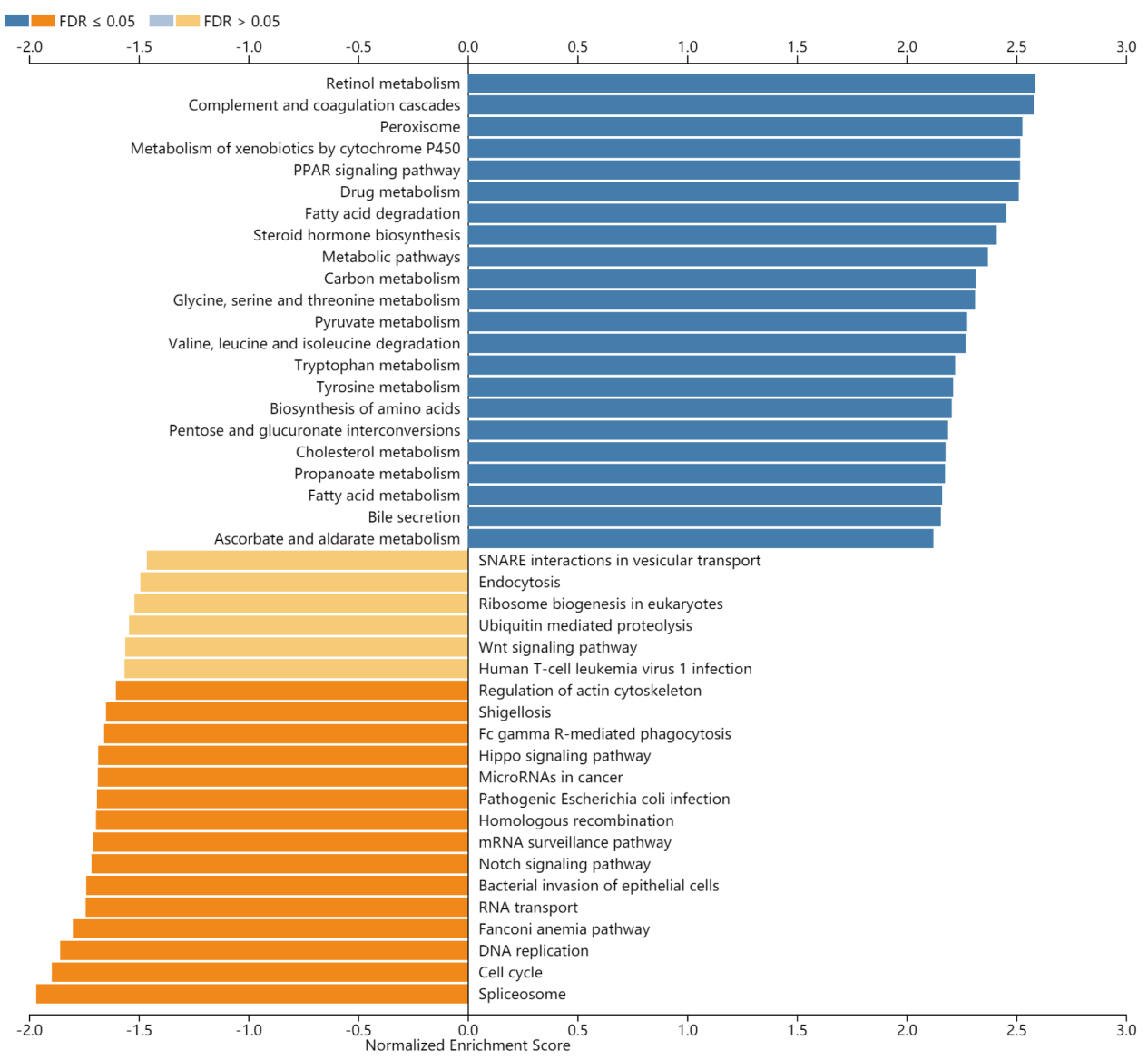

\section{Figure 8}

Enrichment analysis of PCK1 co-expression genes in HCC. (LinkedOmics) Functional enrichment analysis in the PCK1 neighborhood in HCC including biological process (A), cellular components (B), molecular functions (C) and KEGG pathway analysis (D). 


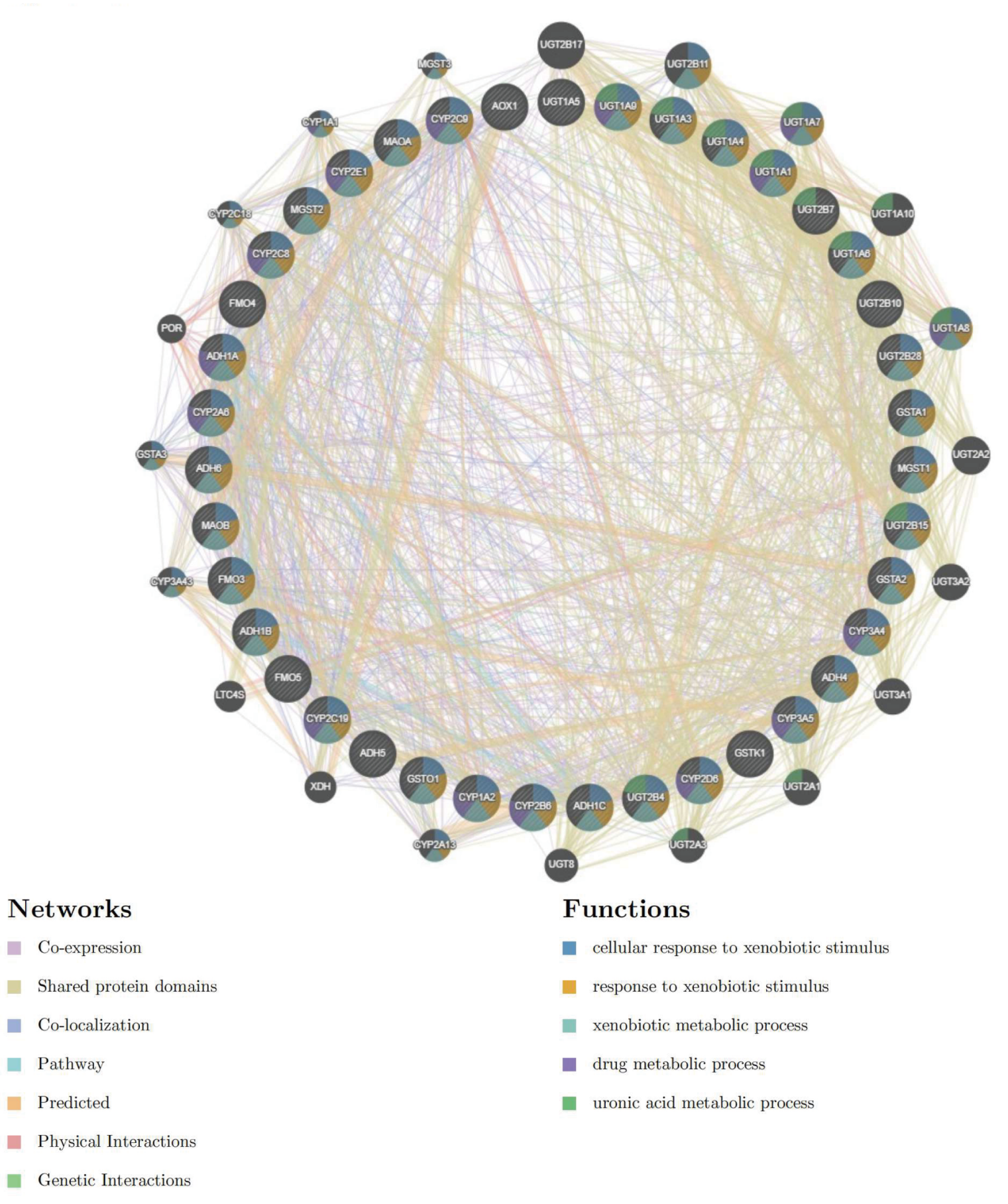

\section{Figure 9}

Protein-protein interaction network of PCK1 targets in HCC (GeneMANIA). Different colors of the network lines present the co-expression, shared protein domains, co-localization, pathway, prediction, physical interactions and genetic interactions. Different colors of the network nodes present the biological functions of PCK1 related genes.

\section{Supplementary Files}


This is a list of supplementary files associated with this preprint. Click to download.

- Sup.Fig1.tif

- Sup.Fig1.tif

- Sup.Fig2.tif

- Sup.Fig2.tif 